\title{
Climate change impact on forest cover and vegetation in Betwa Basin, India
}

\author{
S. S. Palmate $\cdot$ Ashish Pandey $\cdot$ Dheeraj Kumar • \\ R. P. Pandey $\cdot$ S. K. Mishra
}

Received: 10 October 2013/ Accepted: 3 July 2014/ Published online: 29 July 2014

(C) The Author(s) 2014. This article is published with open access at Springerlink.com

\begin{abstract}
This paper evaluates the effect of climate change (described in terms of temperature and rainfall) on forest cover and vegetation (described in terms of Normalized Difference Vegetation Index) in the Betwa river basin, a tributary of River Yamuna in Central India. Temperature and rainfall data of 18 stations, forest cover and vegetation (derived using 5 years data from Landsat images employing ERDAS Imagine and ArcGIS) were used in the analysis. The effect of climate change was studied for both the premonsoon and post-monsoon seasons. In this study, the simple regression method was used to evaluate their relationship. In pre-monsoon season, temperature and forest cover analysis shows regression coefficient value of 0.6876 and, temperature and vegetation analysis shows regression coefficient value of 0.5751 . Further, in post-monsoon season analysis rainfall and forest cover shows regression coefficient value of 0.8417 and, temperature and vegetation analysis shows regression coefficient value of 0.6854 . The study reveals that, in pre-monsoon season temperature was significantly related with forest cover and vegetation. In postmonsoon season rainfall exhibited positive response to forest cover and, temperature exhibited negative response to vegetation in the Betwa river basin.
\end{abstract}

Keywords Climate - Betwa river basin - Climate parameters · Forest cover - Vegetation - NDVI

S. S. Palmate · A. Pandey $(\bowtie) \cdot$ D. Kumar · S. K. Mishra Department of Water Resources Development and Management, Indian Institute of Technology Roorkee, Roorkee 247667, Uttarakhand, India

e-mail: ashisfwt@gmail.com

R. P. Pandey

National Institute of Hydrology, Roorkee 247667, Uttarakhand, India

\section{Introduction}

Climate refers to regular weather conditions of a particular area and climate change involves changes in the frequency and magnitude of extreme events. The climatic parameters include temperature, rainfall, humidity, sunshine hours, cloudiness, pressure, rainfall, number of rainy days, wind velocity etc. Any change in one parameter affects the other directly or indirectly and, in turn, it also affects the living organisms by unbalancing the ecology of the physical environment.

Population increase is known to be the primary reason of regional climate change in India (Pielke et al. 2003). With population growth and human activities, great pressure is being placed on arable land, water, energy, and biological resources to provide an adequate supply of food while maintaining the integrity of our ecosystem. Land use changes are taking place due to rapid urbanisation, changes in river regimes, effects of shifting cultivation, spread of erosion, and desertification. Land use change is directly related with hydrological cycle (Sreenivasulu and Bhaskar 2010) and, any change in land use and shifting cultivation is the major cause for large-scale changes in associated ecosystem (Chakraborty 2009).

The climate change studies in India usually tend to the analysis of climatic parameters only. In southern high altitude regions of India, climate and vegetation seem to have responded to past global climatic changes (Rajagopalan et al. 1997). On the other hand, mountainous forests are susceptible to greater adverse effect of climate change (Gopalakrishnan et al. 2011). Furthermore, the forest cover development depends on the amount of rain received by the area and it, in turn, affects the environment (Tiwari 2006). It implies that the impact of climate change on forest ecosystems is of importance in long-term forest planning (Ravindranath et al. 2006). 
The monsoon precipitation and land surface temperature significantly affect the distribution of vegetation in India (Sarkar and Kafatos 2004). Since vegetation requires moisture, rain and favourable temperatures, it may characterise the regional weather. For large areas comprising vegetation, Normalized Difference Vegetation Index (NDVI) method is better suitable where analysis is carried out using either past or present images with no ground truth data (Chandrabose et al. 2012). Vegetation and land use/ land cover changes are closely correlated with precipitation changes on a seasonal scale which, in turn, have feedback on the regional climate. Aerosols alter sunlight that reaches vegetation, affecting carbon assimilation and transpiration.

In the past two decades, remote sensing (RS) and geographical information system (GIS) techniques are used extensively to detect the type of changes, location of changes, and quantification of changes in land use/land cover. Notably, image analysis by RS can provide a direct record on long/short term impact on land use/land cover in recent or past (Joshi and Nagare 2009). The potential of Landsat image data is to provide an accurate classification for land cover changes over time (Tsarouchi and Buytaert 2013). Also, the change detection through RS means the change in spectral signatures commensurate with the change in land cover. Change detection can be precisely determined using GIS due to its high volume of spatial and non-spatial data handling capabilities (Sakthivel et al. 2010).

Rainfall and temperature pattern are varying and, atmospheric $\mathrm{CO}_{2}$ concentrations is increasing due to anthropogenic activities contributing to climate change. Therefore, study on effect of climate changes in forest area and vegetation is essential to indentify the ecosystem functions in the river basin for proper planning and management. It is evident from the recent review of literature that only a little or no research work has been directed towards the study of the effects of climate change on forest and vegetation cover. Therefore, this study attempts to (a) estimation of total vegetation and forest cover area over Betwa river basin using satellite data and (b) evaluate the impact of climate change on vegetation.

\section{Study area}

Betwa river basin (BRB) (earlier known as Betravati River) is the tributary of River Yamuna in Central India (Fig. 1). Betwa River originates from Barkhera in Raisen district of Madhya Pradesh State. This interstate river passes through Madhya Pradesh and Uttar Pradesh. It flows in a north-east direction through Madhya Pradesh and enters Uttar Pradesh near Bangawan of Jhansi district. From origin to confluence with River Yamuna, the total length of Betwa River is
$590 \mathrm{~km}$, out of which $232 \mathrm{~km}$ lies in Madhya Pradesh, and $358 \mathrm{~km}$ in Uttar Pradesh. It joins Yamuna near Hamirpur in Uttar Pradesh at an elevation of about $106 \mathrm{~m}$. BRB is bounded by northern alluvial plains and southern Vindhyan plateau. River extends from $22^{\circ} 54^{\prime} 00^{\prime \prime} \mathrm{N}$ to $26^{\circ} 00^{\prime} 00^{\prime \prime} \mathrm{N}$ latitudes and $77^{\circ} 10^{\prime} 00^{\prime \prime} \mathrm{E}$ to $80^{\circ} 20^{\prime} 00^{\prime \prime} \mathrm{E}$ longitudes and covers five districts of southern Uttar Pradesh (Jalaun, Hamirpur, Jhansi, Mahoba, and Lalitpur) and ten districts of Madhya Pradesh (Shivpuri, Ashoknagar, Guna, Tikamgarh, Chhatarpur, Sagar, Vidisha, Bhopal, Sehore and Raisen) (Ahlawat 2010). From the total catchment area about $43,895 \mathrm{~km}^{2}$ of BRB, 30,217 $\mathrm{km}^{2}$ area lies in Madhya Pradesh, and remaining $13,678 \mathrm{~km}^{2}$ area in Uttar Pradesh.

\section{Methodology}

In this study, temperature, rainfall, forest cover and vegetation data were used to establish their relationship. The daily climate data described in terms of temperature and rainfall were taken from Indian Water Portal website (http://www.indiawaterportal.org) and for forest cover and vegetation, satellite imagery of Landsat 4-5 TM (Thematic Mapper) and Landsat 7 ETM+ (Enhanced Thematic Mapper) plus type data was downloaded from the USGS website (http://glovis.usgs.gov/) for the years 1998, 2000, 2002, 2009, and 2011.

Images were selected for pre-monsoon and post-monsoon season exhibiting minimum interference of cloud cover. Figure 2 shows the flowchart of methodology adopted in this study.

BRB falls in six scenes of satellite images. Downloaded images were stacked and then mosaiced using ERDAS Imagine V2012 software. The correction of satellite images includes radiometric correction based on the radiance and geometric corrections based on the digital number, were performed for all the images. Radiometric correction used to remove sensor or atmospheric noise and to represent accurate ground conditions in an image (Zhang et al. 1999). Also, geometric correction used to remove distortion prevention by the rectification of an image (Wie and Stein 1977). The area of interest (AOI) was prepared for the BRB to extract required study area from mosaiced images. In this study, the supervised Maximum Likelihood classification was applied for mapping land use and land cover (LU/LC) of the study area. Visual survey of the study area was carried out to identify signatures of various objects and land use classes in the raw image. In unsupervised classification, each extracted image was processed by the software and depending on similarities; pixels were distinguished in hundred different classes. Each class covering forest area was identified in ArcGIS V10.1 software and then reclassified to add them in forest cover class 
Fig. 1 Betwa River Basin (BRB)

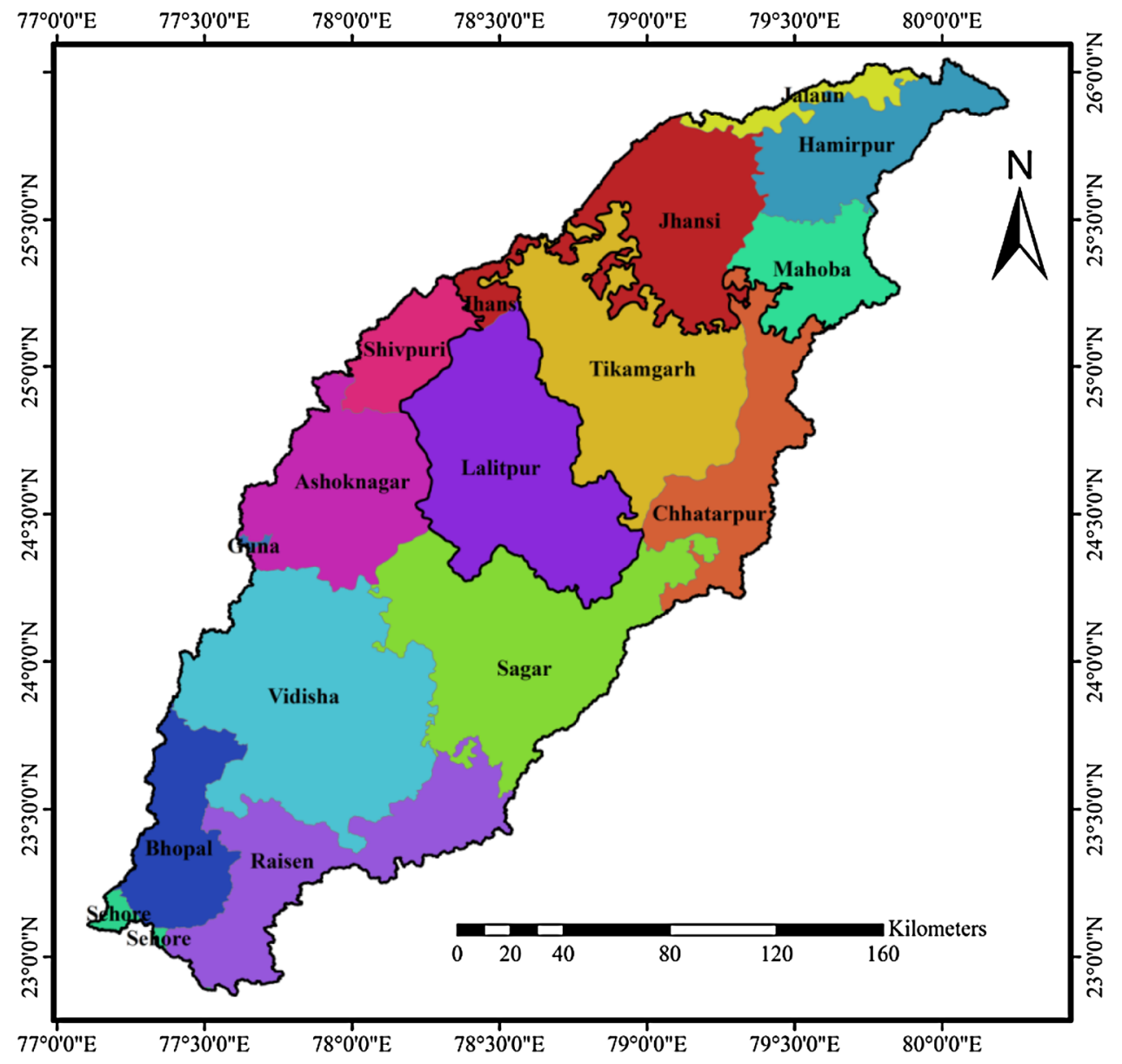

between 77 and $87 \%$ and Kappa coefficient $(\hat{\mathrm{k}})$ ranges from 0.6252 to 0.7614 for classified imageries. Classified maps for each season within that years are presented as shown in Fig. 3.

Different vegetation indices have been used for the vegetation monitoring. The popular NDVI method was used for monitoring temporal changes in vegetation of the BRB. It has been used to prepare spectral vegetation indices which separate green vegetation using Landsat data. This method depends on the different interactions between electromagnetic spectrum of near-infrared and red wavelengths. Red wavelength (about 0.6-0.7 $\mu \mathrm{m}$ ) shows low reflectance because chlorophyll of leaf pigment absorbs more red wavelengths and infrared wavelength (about $0.8-0.9 \mu \mathrm{m}$ ) is of high reflectance because cell structure of the leaves scatters more infrared wavelength. NDVI can easily determine with the comparison of infrared wavelength band to that of red wavelength band. NDVI is the ratio of difference between the near-infrared and red wavelength bands and sum of those two bands. It is expressed as follows (Richardson and Everitt 1992):

$\mathrm{NDVI}=\left(\frac{\mathrm{NIR}-\mathrm{RED}}{\mathrm{NIR}+\mathrm{RED}}\right)$ of all the imageries was carried out using ERDAS Imagine software. The overall classification accuracy varies

Fig. 2 Flowchart of methodology used for establishment of relationship

of supervised classification. Further, accuracy assessment 


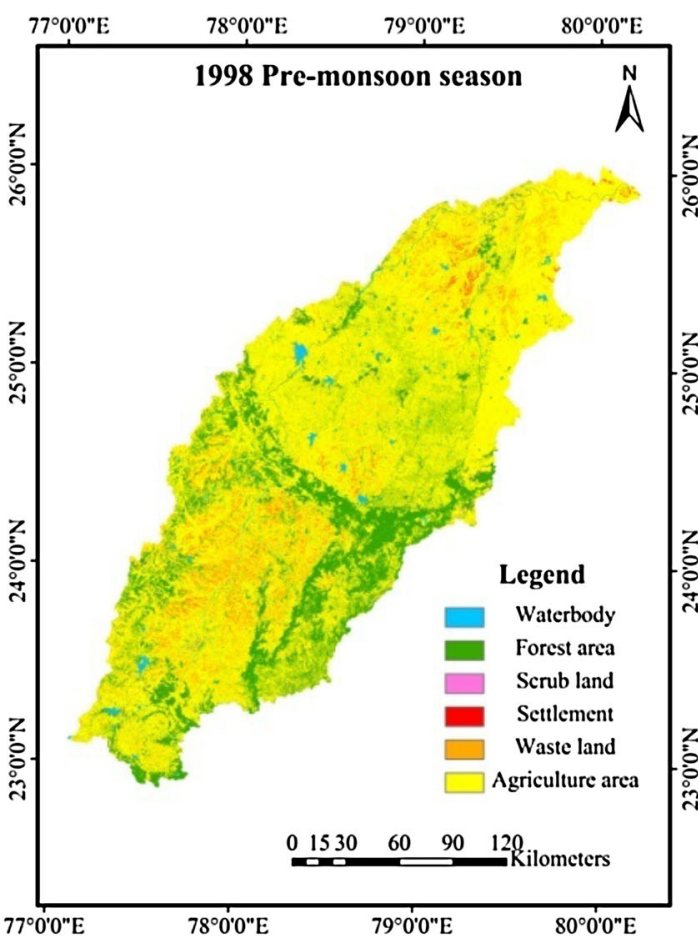

(a) 1998 pre-monsoon season

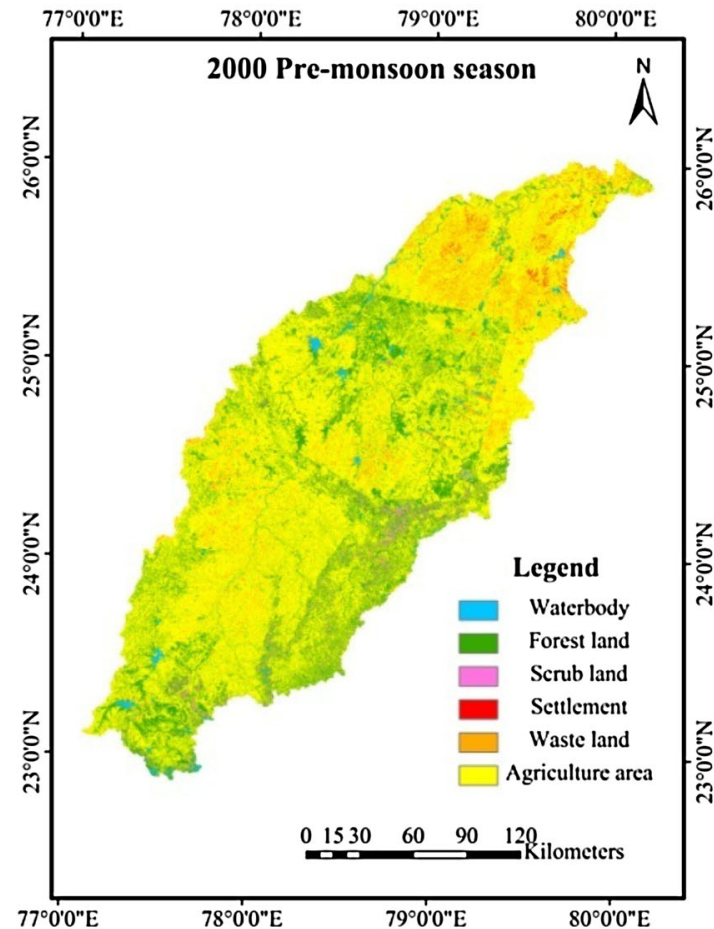

(c) 2000 pre-monsoon season

Fig. 3 LU/LC classification maps for Betwa river basin: a 1998 premonsoon season, b 1998 post-monsoon season, c 2000 pre-monsoon season, d 2000 post-monsoon season, e 2002 pre-monsoon season,

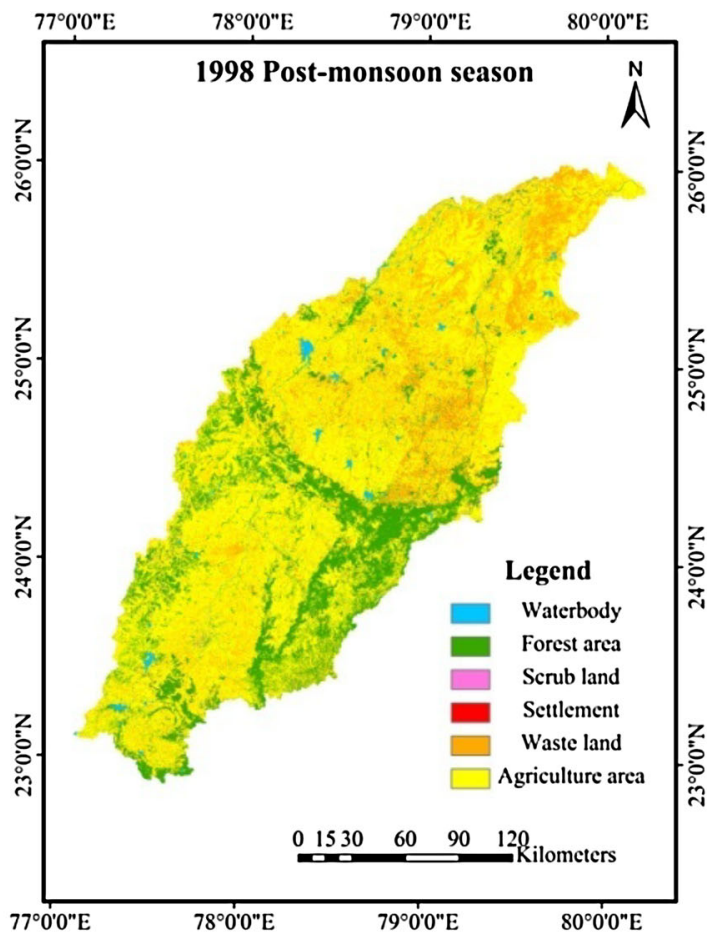

(b) 1998 post-monsoon season

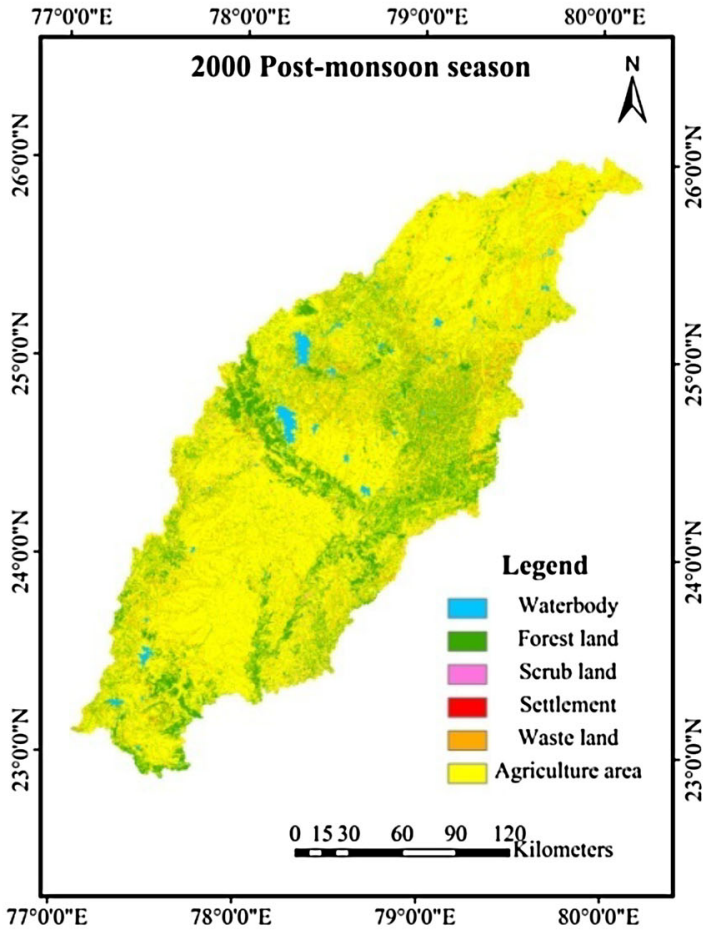

(d) 2000 post-monsoon season

f 2002 post-monsoon season, g 2009 pre-monsoon season, h 2009 post-monsoon season, i 2011 pre-monsoon season, j 2011 postmonsoon season 


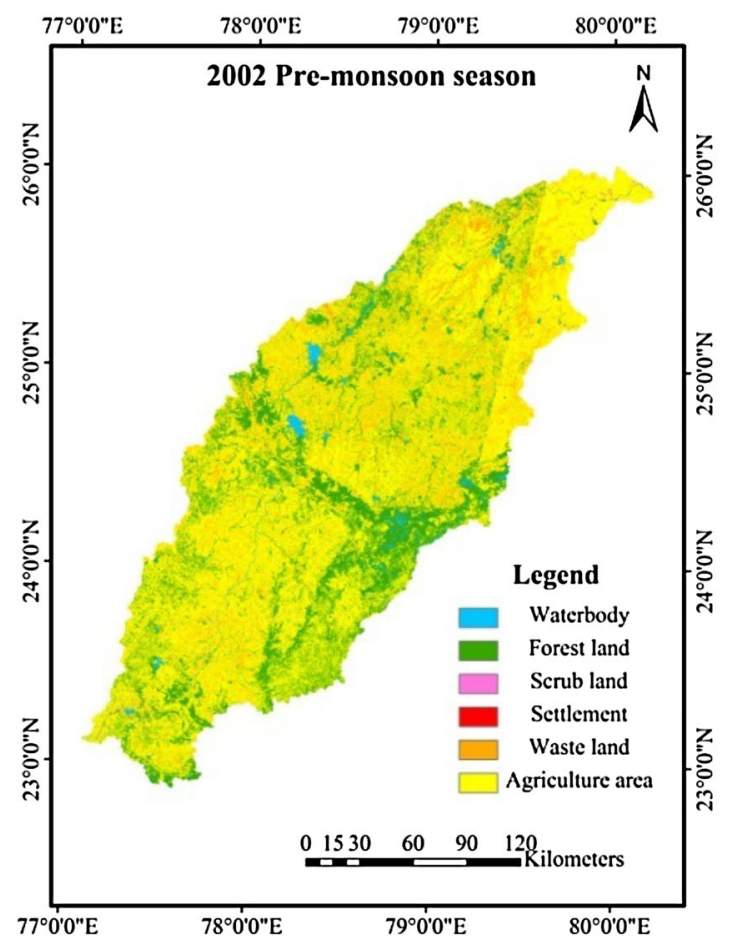

(e) 2002 pre-monsoon season

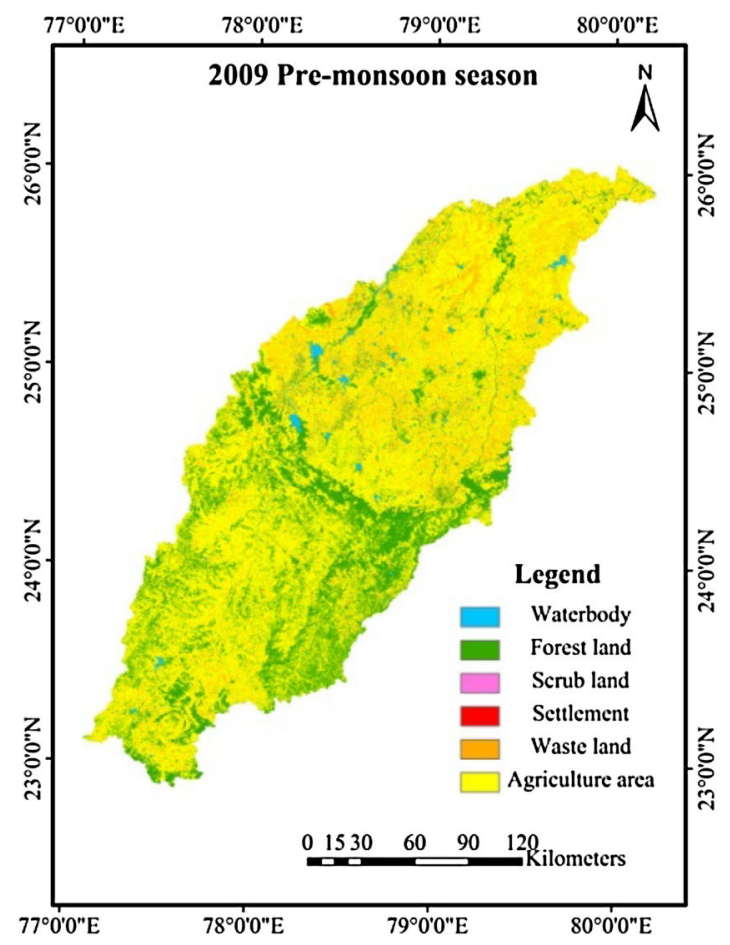

(g) 2009 pre-monsoon season

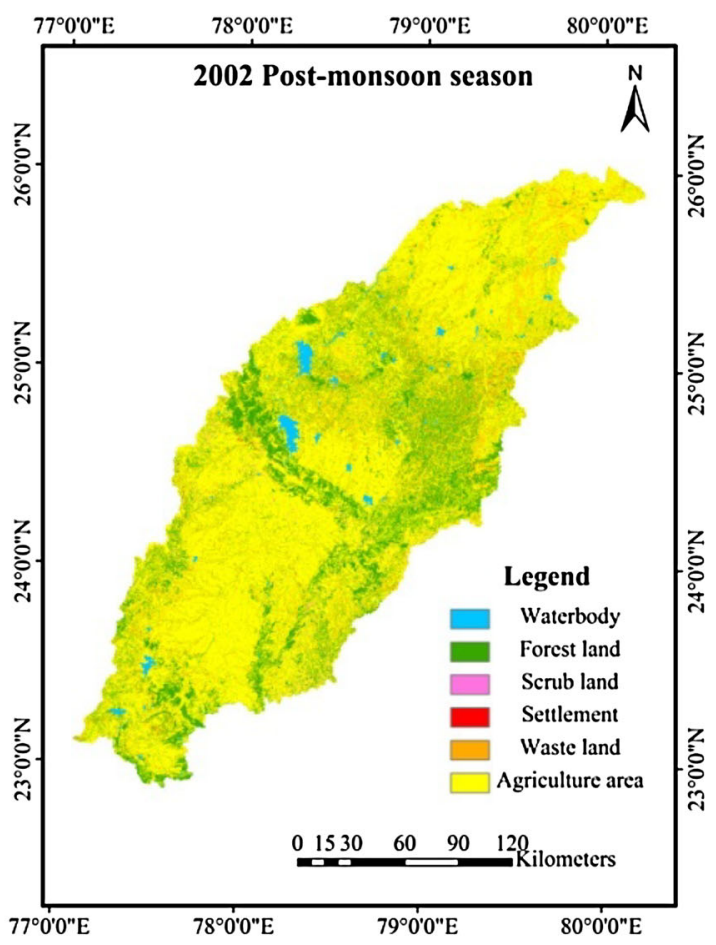

(f) 2002 post-monsoon season

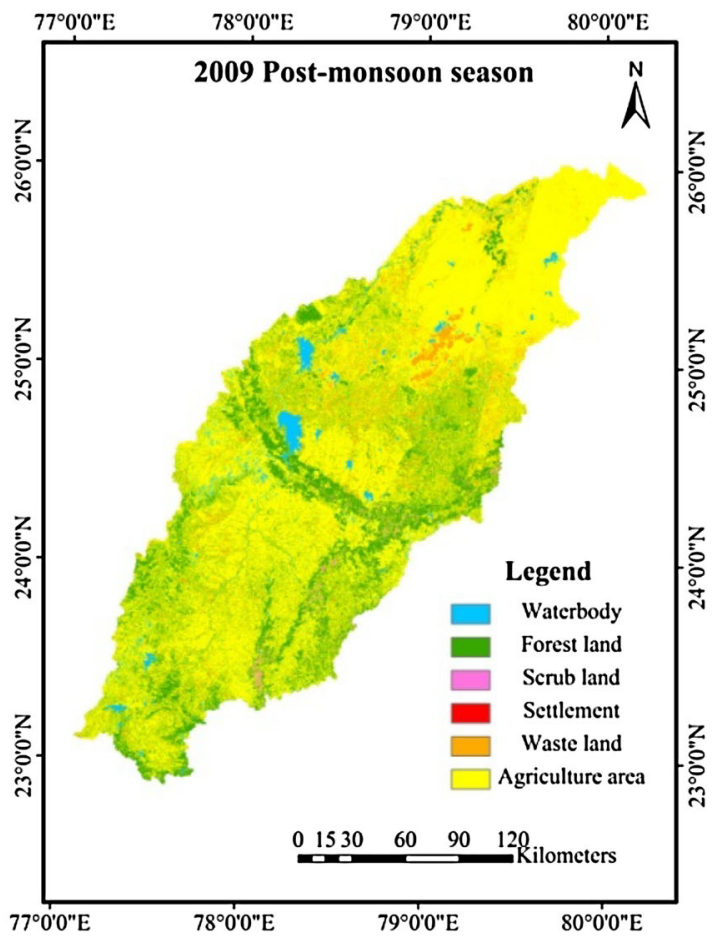

(h) 2009 post-monsoon season

Fig. 3 continued 


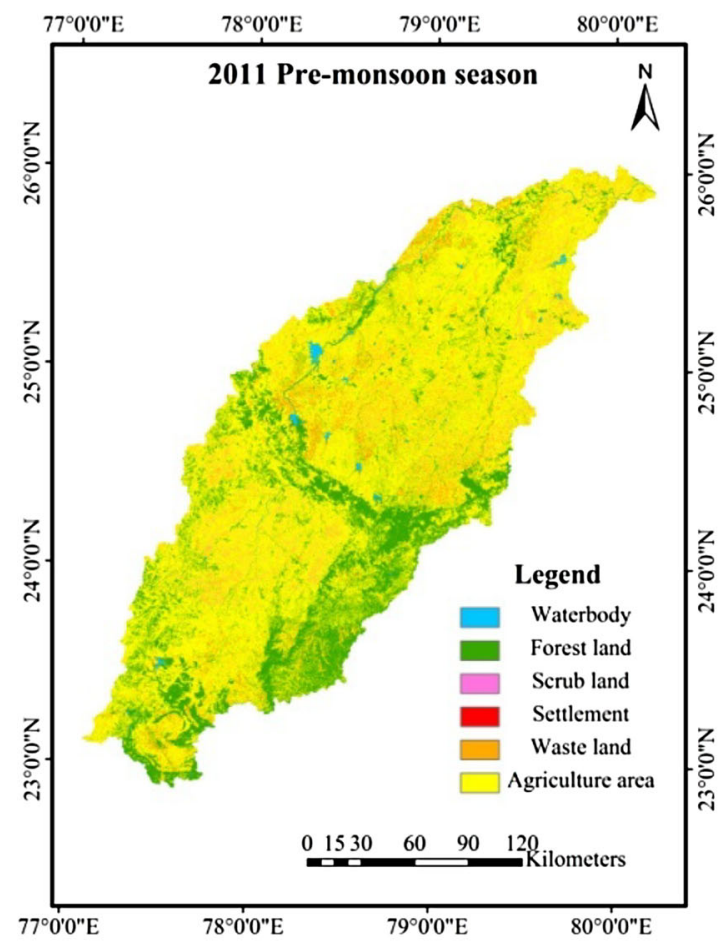

(i) 2011 pre-monsoon season

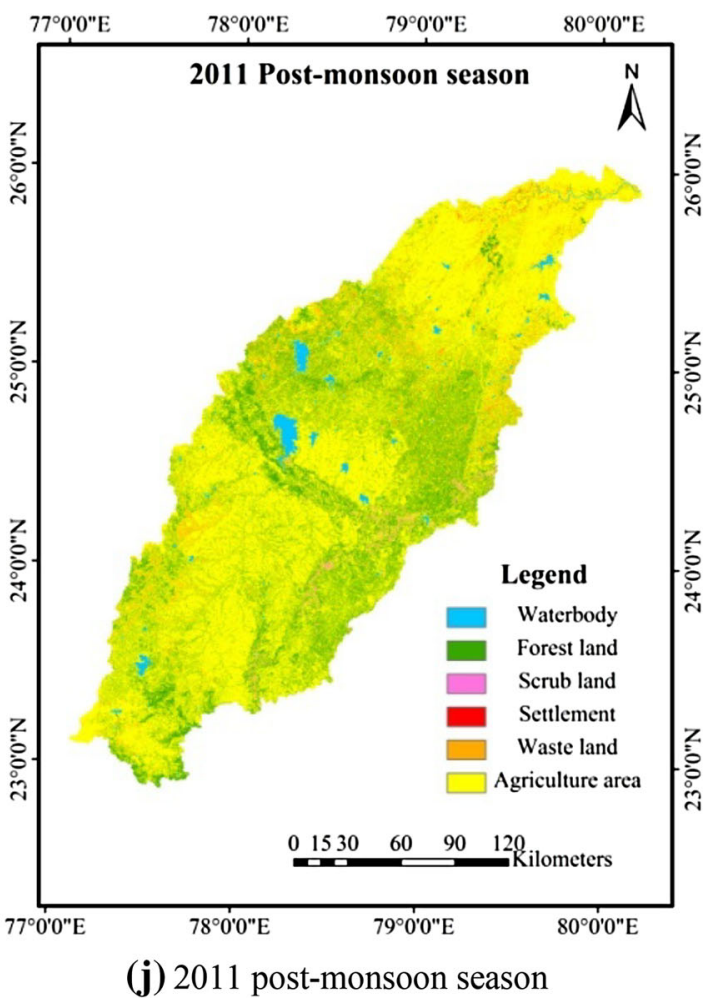

Fig. 3 continued

where NDVI is Normalized Difference Vegetation Index, NIR is Near Infra Red colour spectral band and RED is Red colour spectral band.

This is the most commonly used VI; it has the value in the range of -1 to 1 . NDVI value range from -1 to 0 depicts no vegetation and the value range from 0 to 1 depicts vegetation. With the use of two spectral bands red (RED) and near-infrared (NIR), NDVI computes total vegetation coverage area of the basin. This approach of using spectral data improves the utility of predictive change relations for vegetation (Richardson and Everitt 1992). Also, it demonstrates the best vegetation change detection (Lyon et al. 1998). In this study, values of NDVI were computed using NIR (Band 4) and RED (Band 3) bands of Landsat imagery.

NDVI values were calculated using ArcGIS raster calculator and maps of the BRB were prepared as shown in Fig. 4. In this study, forest cover area, agriculture area, grassland and scrubland are taken into consideration for vegetation class category. As per imagery seasonal dates, seasonal averages of rainfall and temperature were derived for the respective years.

Regression analysis method was used to describe the relationship between two dependent variables (forest cover and vegetation) and two independent variables (temperature and rainfall). The simple linear regression method uses one variable and test the response of another variable to it. In this method, regression coefficient value exhibit relationship and their change response. This technique has been used to investigate relationships between two variables associated with their change.

\section{Results and discussion}

The results obtained from analysis of the climatic data and satellite data are discussed in this section. Tables 1 and 2 show the values of seasonal average of temperature $\left({ }^{\circ} \mathrm{C}\right)$, rainfall $(\mathrm{mm})$, forest cover (million hectares) and NDVI. Further, daily climatic data of 5 years $(1998,2000,2002$, 2009 and 2011) were used to calculate their pre-monsoon and post-monsoon seasonal averages. Using satellite data, forest cover area was obtained by image classification and total vegetation was obtained by NDVI method.

\section{Pre-monsoon season}

Table 1 show the pre-monsoon seasonal values of temperature $\left({ }^{\circ} \mathrm{C}\right)$, rainfall $(\mathrm{mm})$, forest cover (million hectares) and NDVI. Relationship between two variables associated with their changes were analysed graphically and presented in Figs. 5 and 6 . Figures 5 and 6 shows relationship between 


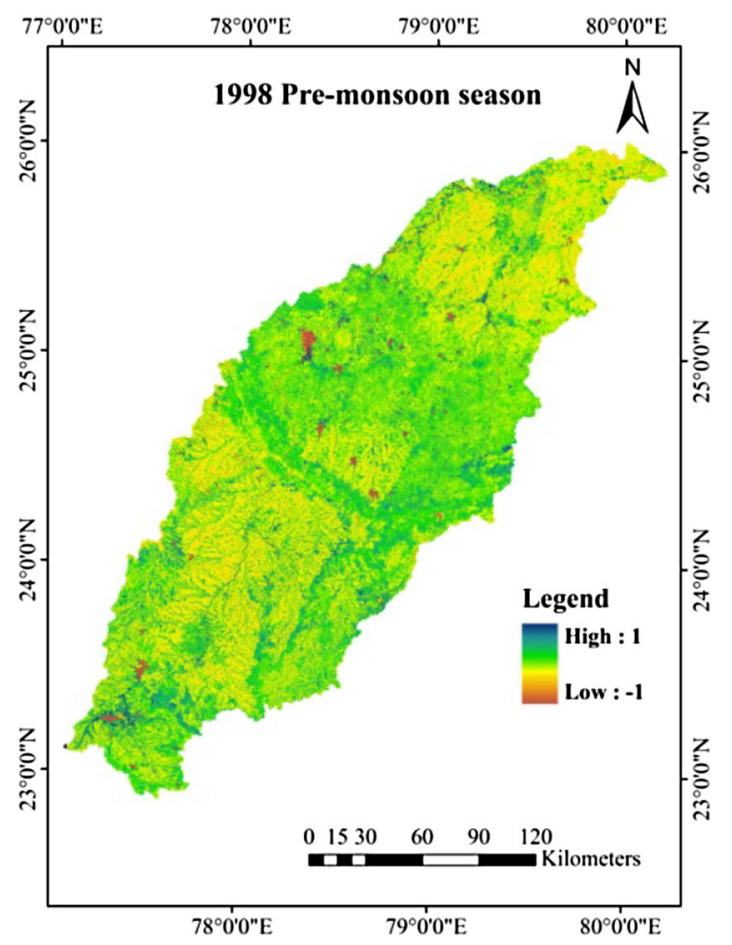

(a) 1998 pre-monsoon season

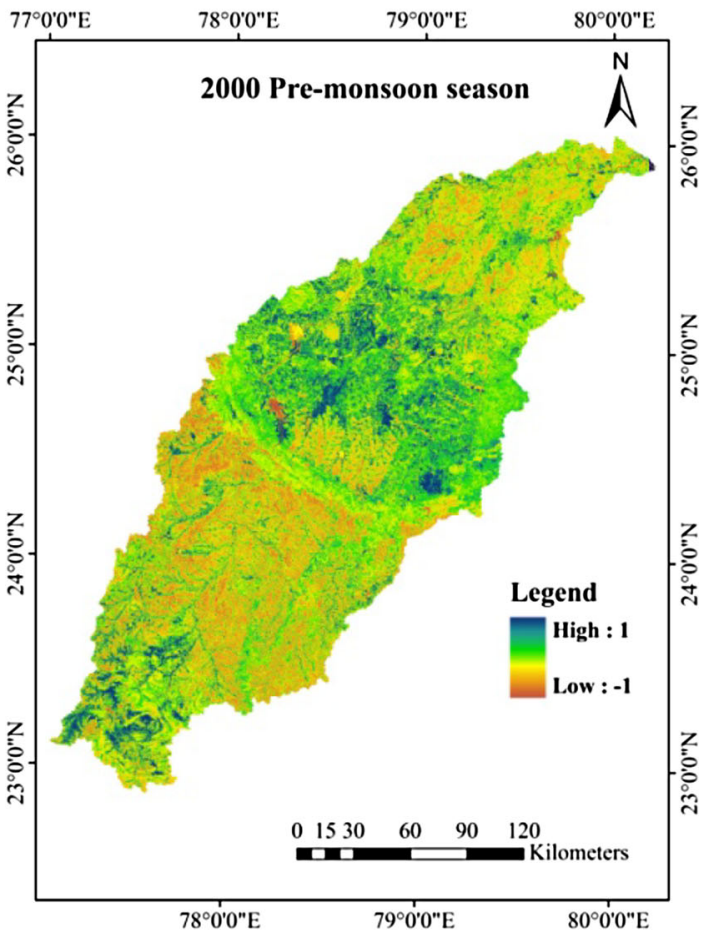

(c) 2000 pre-monsoon season

Fig. 4 NDVI maps for the Betwa river basin: a 1998 pre-monsoon season, b 1998 post-monsoon season, c 2000 pre-monsoon season, d 2000 post-monsoon season, e 2002 pre-monsoon season, f 2002

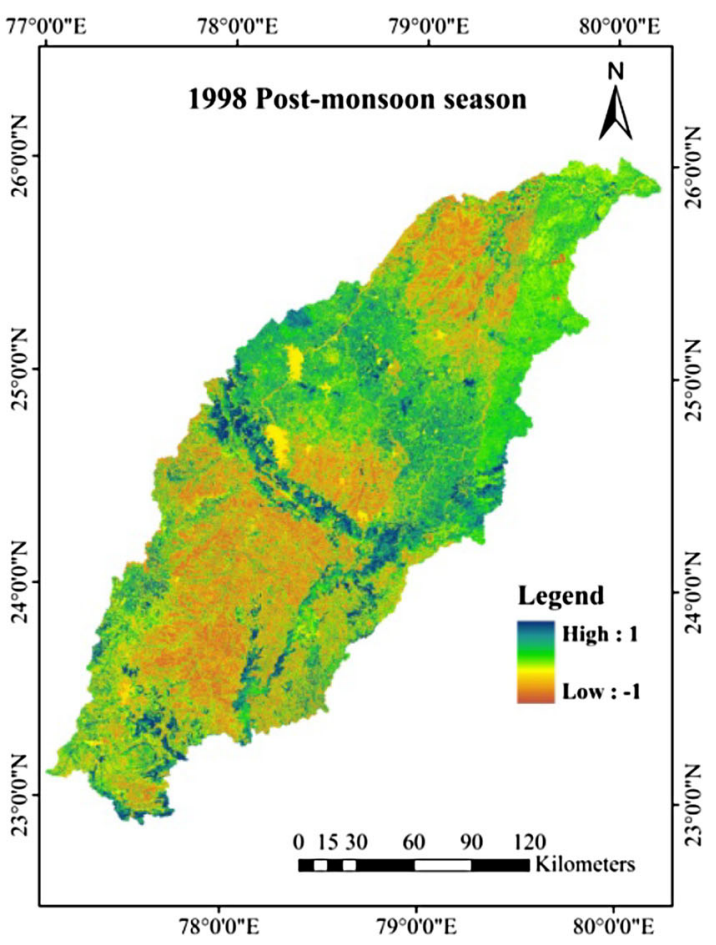

(b) 1998 post-monsoon season

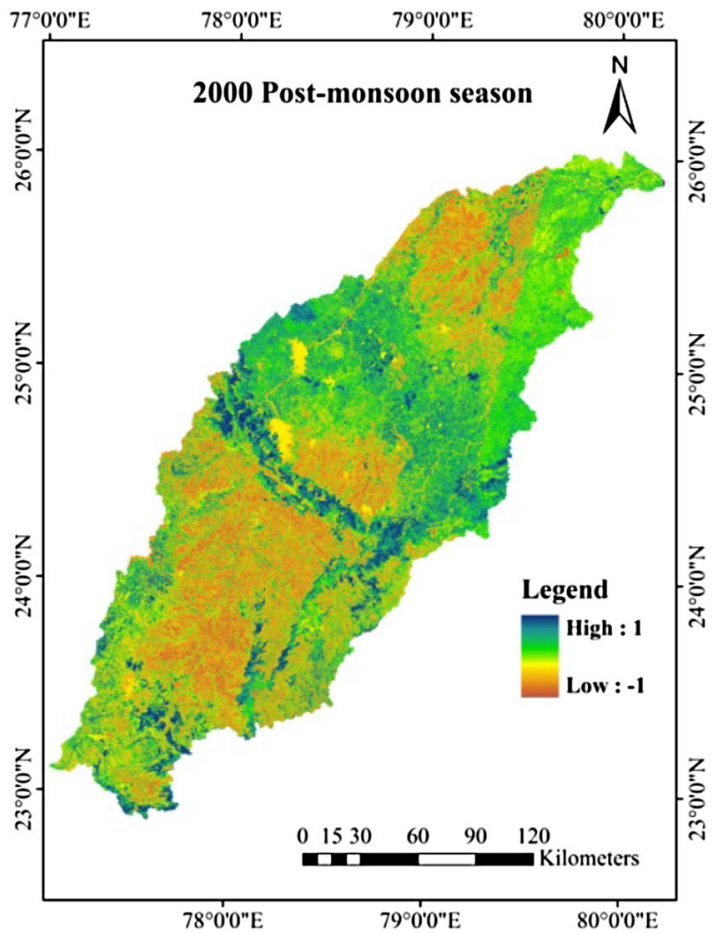

(d) 2000 post-monsoon season

post-monsoon season, g 2009 pre-monsoon season, h 2009 postmonsoon season, i 2011 pre-monsoon season, j 2011 post-monsoon season 


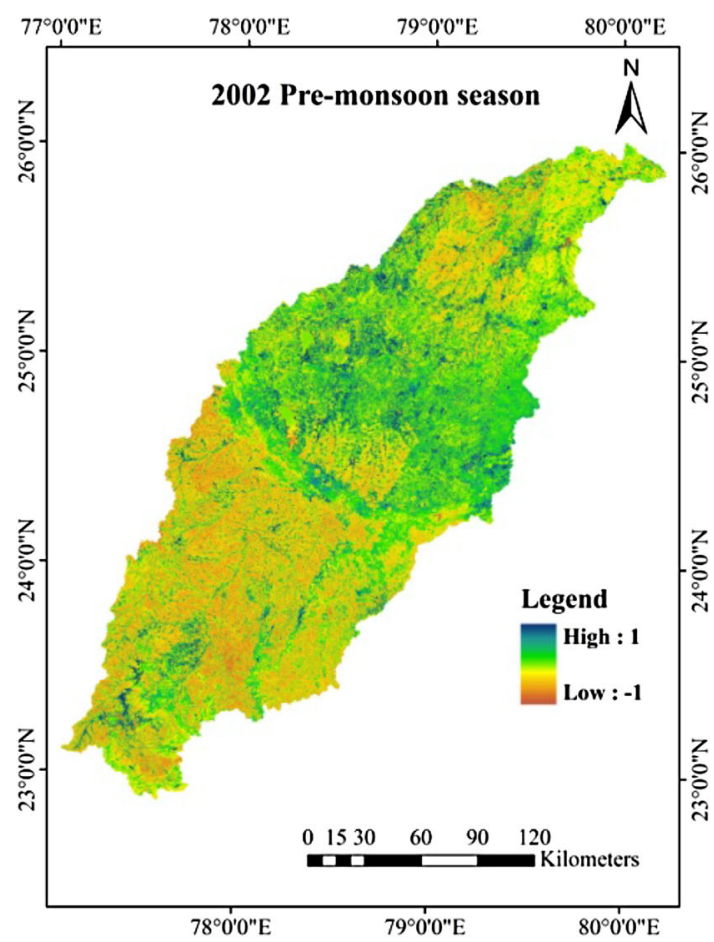

(e) 2002 pre-monsoon season

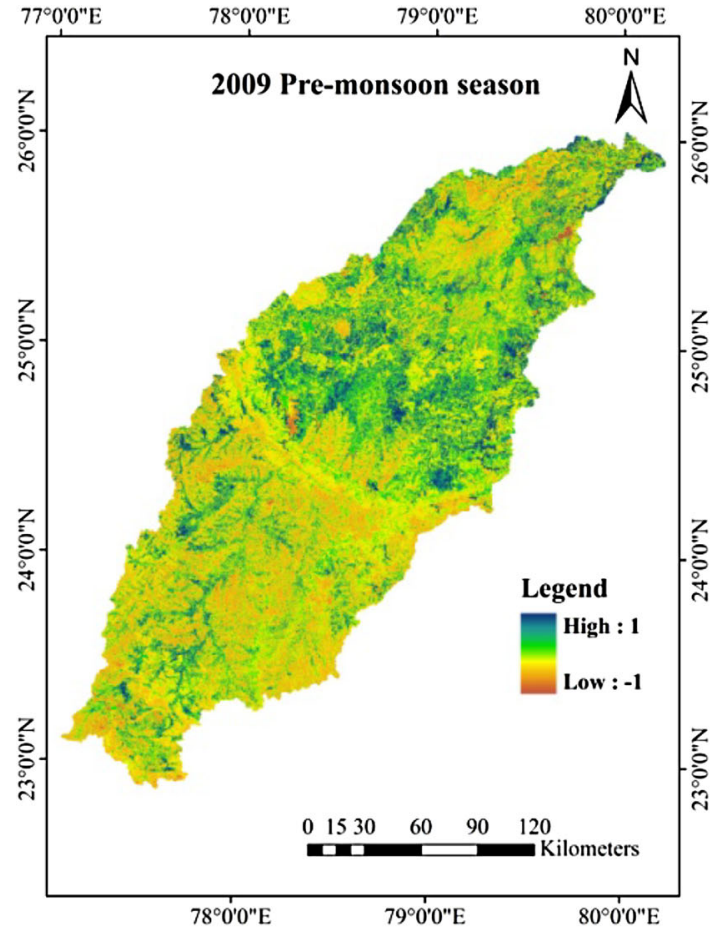

(g) 2009 pre-monsoon season

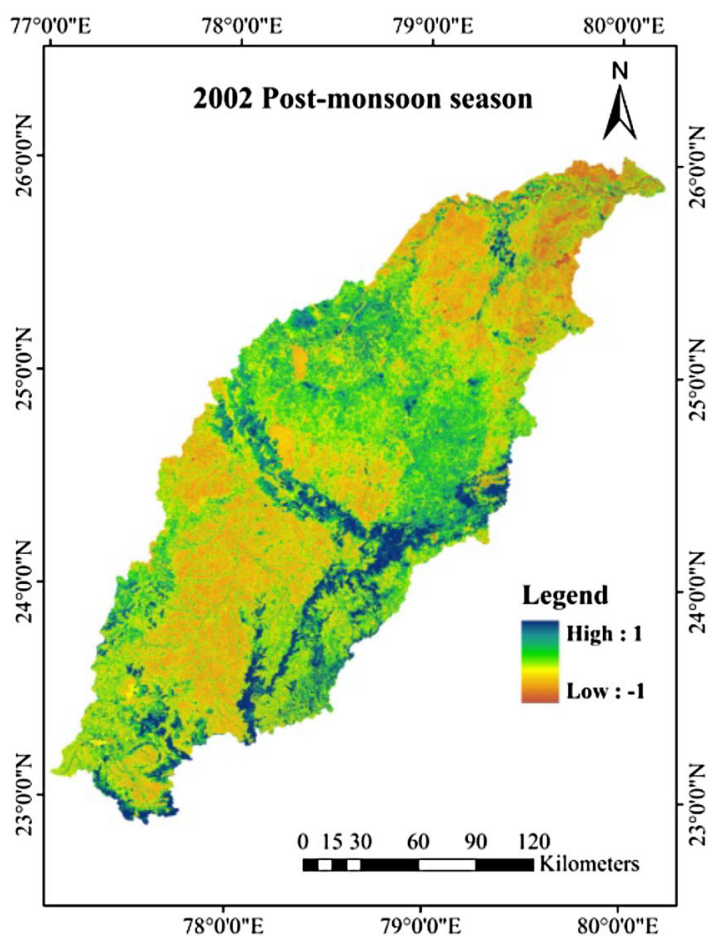

(f) 2002 post-monsoon season

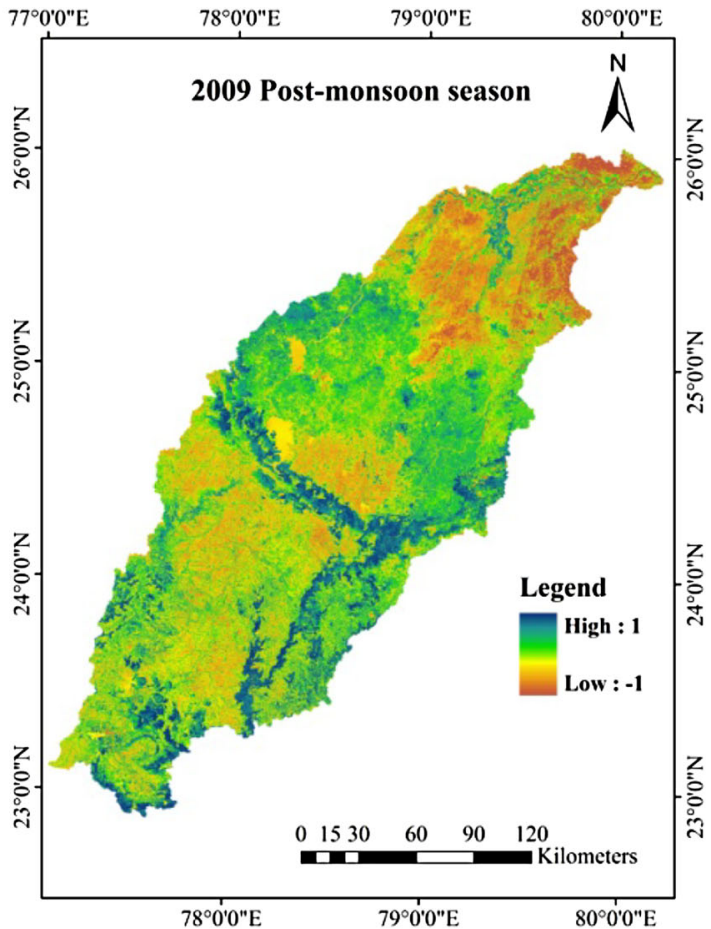

(h) 2009 post-monsoon season

Fig. 4 continued 


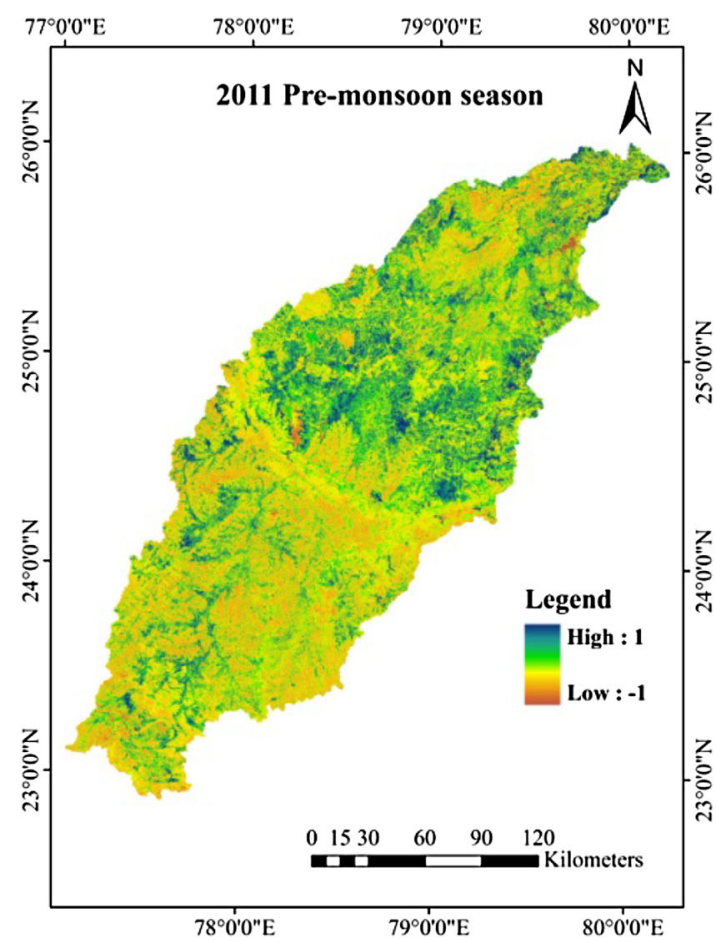

(i) 2011 pre-monsoon season

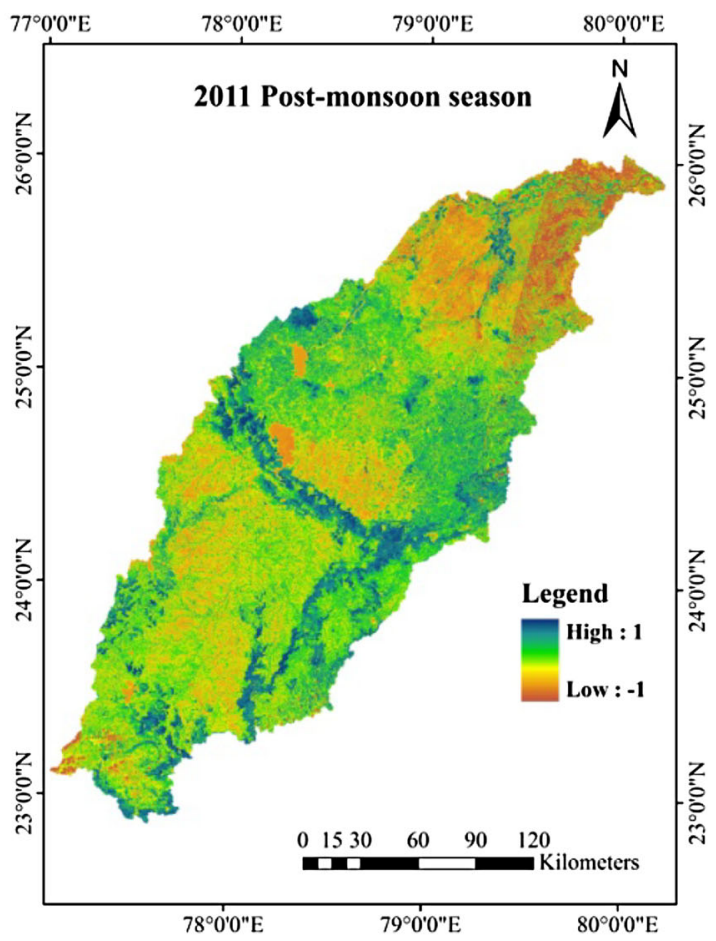

(j) 2011 post-monsoon season

Fig. 4 continued

Table 1 Relationship between forest cover, vegetation and climate parameters in Betwa river basin (pre-monsoon season)

\begin{tabular}{lllll}
\hline $\begin{array}{l}\text { Year } \\
\mathrm{Y}\end{array}$ & $\begin{array}{l}\text { Mean } \\
\text { temperature }\left({ }^{\circ} \mathrm{C}\right)\end{array}$ & $\begin{array}{l}\text { Mean rainfall } \\
(\mathrm{mm}) \\
\mathrm{R}\end{array}$ & $\begin{array}{l}\text { Forest cover } \\
(\mathrm{M} \text { ha })\end{array}$ & $\begin{array}{l}\text { Vegetation } \\
\text { NDVI }\end{array}$ \\
\hline 1998 & 25.248 & 117.611 & 0.915 & 0.422 \\
2000 & 24.218 & 97.767 & 0.933 & 0.333 \\
2002 & 24.878 & 107.706 & 0.967 & 0.357 \\
2009 & 27.915 & 151.606 & 1.023 & 0.422 \\
2011 & 26.377 & 276.831 & 0.967 & 0.422 \\
\hline
\end{tabular}

Table 2 Relationship between forest cover, vegetation and climate parameters in Betwa river basin (post-monsoon season)

\begin{tabular}{lllll}
\hline $\begin{array}{l}\text { Year } \\
\mathrm{Y}\end{array}$ & $\begin{array}{l}\text { Mean } \\
\text { temperature }\left({ }^{\circ} \mathrm{C}\right)\end{array}$ & $\begin{array}{l}\text { Mean rainfall } \\
(\mathrm{mm}) \\
\mathrm{R}\end{array}$ & $\begin{array}{l}\text { Forest cover } \\
(\mathrm{M} \text { ha })\end{array}$ & $\begin{array}{l}\text { Vegetation } \\
\text { NDVI }\end{array}$ \\
\hline 1998 & 22.932 & 744.256 & 0.958 & 0.460 \\
2000 & 23.554 & 428.091 & 0.861 & 0.357 \\
2002 & 23.694 & 612.983 & 0.956 & 0.333 \\
2009 & 25.640 & 739.339 & 0.971 & 0.288 \\
2011 & 25.334 & 724.389 & 0.947 & 0.322 \\
\hline
\end{tabular}
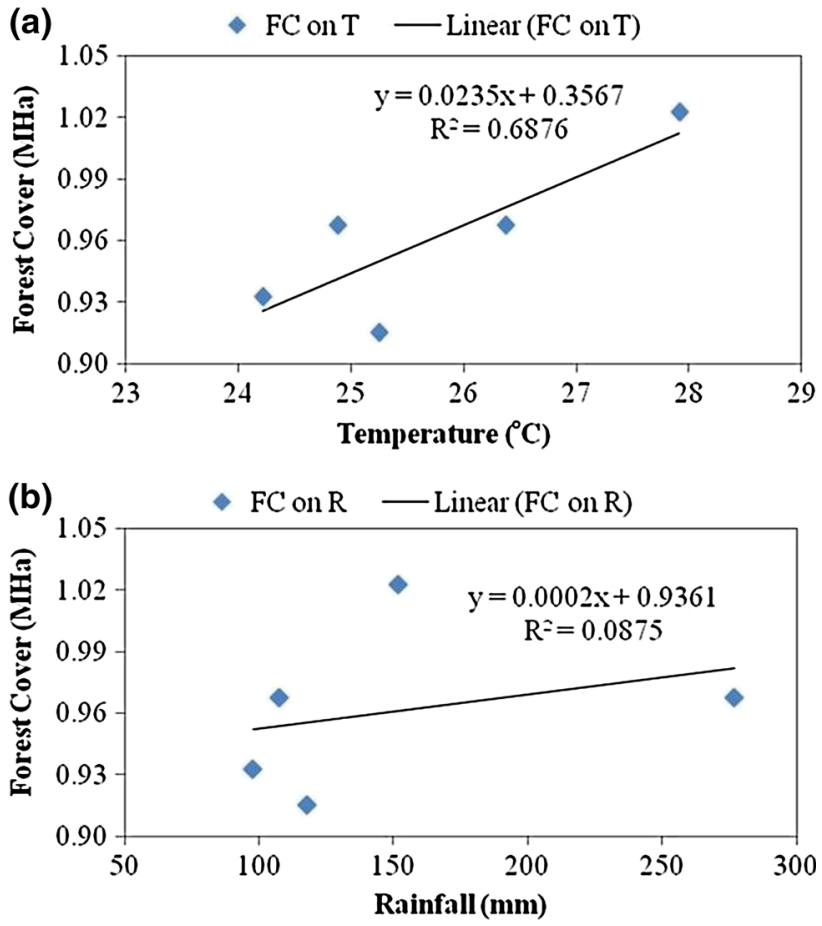

Fig. 5 Graphical relationship (Pre-monsoon season): a between forest cover and temperature, $\mathbf{b}$ between forest cover and rainfall 
climatic variables (rainfall, temperature) and, forest cover and vegetation variables exhibited a direct relationship.

Figure 5 depicts the graphical relationship between climatic variables and forest cover. Regression analysis between temperature and forest cover shows a moderate regression coefficient value of 0.6876 (Fig. 5a) and exhibited a significant relationship. Similarly, Regression analysis between rainfall and forest cover shows a lower regression coefficient value of 0.0875 (Fig. 5b) and indicates poor correlation between rainfall and forest cover.

Figure 6 depicts the graphical representation of climatic variables and vegetation obtained through NDVI. Regression analysis between temperature and vegetation shows a moderate regression coefficient value of 0.5751 (Fig. 6a) and exhibited a significant relationship. Similarly, regression analysis between rainfall and vegetation shows low regression coefficient value of 0.3459 (Fig. 6b).

The above analysis showed a significant relationship of temperature with vegetation and forest cover in pre-monsoon season. Both forest cover and vegetation have a moderate response to temperature. During pre-monsoon season, water provides nutrient to the plants and trees, and other biological activities of vegetation growth moderately respond to temperature in the BRB.

The results obtained from above analysis shows that, for pre-monsoon season the relationship of temperature with forest cover and vegetation is significant in the Betwa river basin. However, there is no significant relationship of rainfall with forest cover and vegetation under changing climate scenario.

Influence of rainfall on forest cover and NDVI is in the same response direction. In the Betwa river basin, small changes in forest cover and vegetation are due to anthropogenic activities in the river basin.

\section{Post-monsoon season}

Table 2 shows the post-monsoon seasonal values of temperature $\left({ }^{\circ} \mathrm{C}\right)$, rainfall $(\mathrm{mm})$, forest cover (million ha) and NDVI. Relationship between two variables associated with their changes are also analysed graphically and presented in Figs. 7 and 8.

Figure 7 depicts the graphical relationship between climatic variable and forest cover. Regression analysis between temperature and forest cover shows a low regression coefficient value of 0.1206 (Fig. 7a). Similarly, Regression analysis between rainfall and forest cover shows a high regression coefficient value of 0.8417 (Fig. 7b) and exhibited a significant relationship.

Figure 8 depicts the graphical relationship of climatic variable and vegetation. Regression analysis between
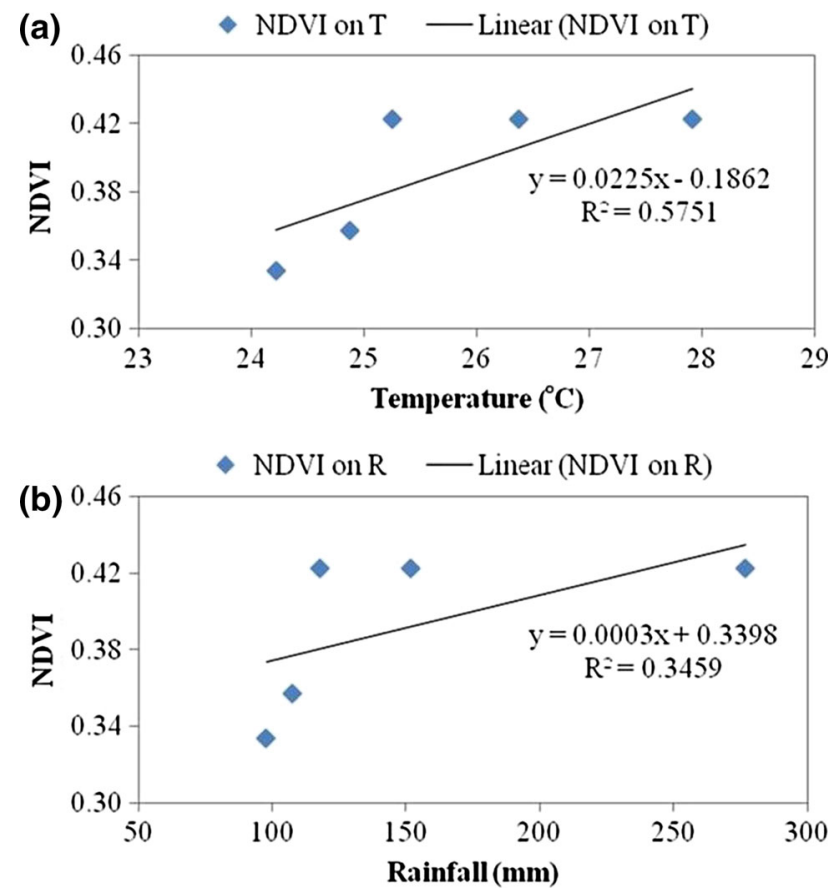

Fig. 6 Graphical relationship (Pre-monsoon season): a between NDVI and temperature, b between NDVI and rainfall
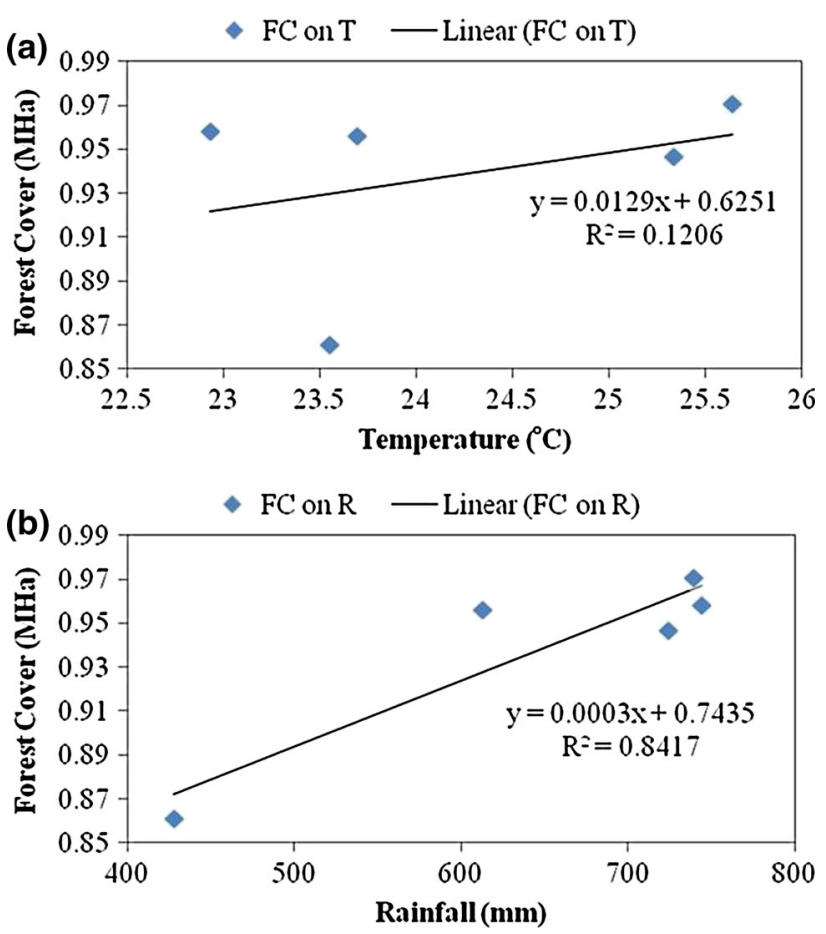

Fig. 7 Graphical relationship (post-monsoon season): a between forest cover and temperature, $\mathbf{b}$ between forest cover and rainfall

temperature and vegetation shows a moderate regression coefficient value of 0.6854 (Fig. 8a) and exhibited a significant relationship. Similarly, Regression analysis between 

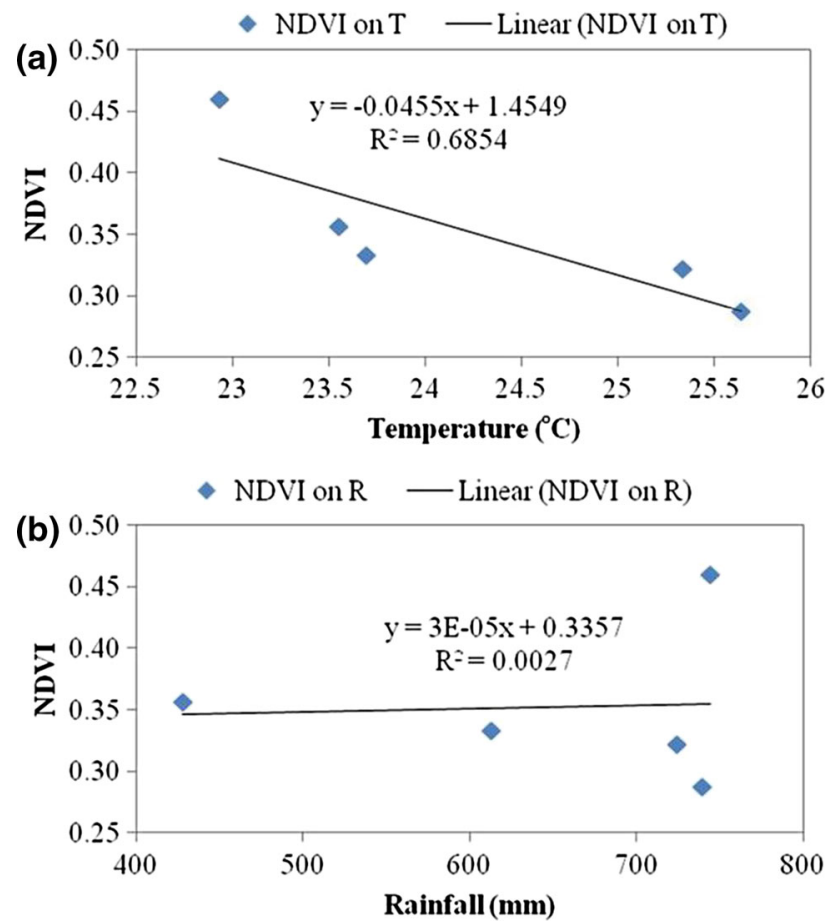

Fig. 8 Graphical relationship (post-monsoon season): a between NDVI and temperature, $\mathbf{b}$ between NDVI and rainfall

rainfall and vegetation shows a low regression coefficient value of 0.0027 (Fig. 8b).

In post-monsoon season, water requirement of plants is sufficiently fulfilled due to monsoon rainfall. Rainfall helps to retain adequate moisture availability in soil so that the plant roots can easily extract water from soil for their growth. Hence, relationship between rainfall and forest cover resulted high regression coefficient which prevails increase in forest cover in post-monsoon season.

The temperature responded inversely to the vegetation cover for the present study area. It means rise in temperature reduced moisture availability of soil in post-monsoon season and decrease in water requirement of crop resulted in low vegetation growth.

The results obtained through the above analysis shows that the relationship of rainfall with forest cover and temperature with vegetation are significant in post-monsoon season for the Betwa river basin. Relationship of vegetation to temperature is inversely related in post-monsoon season; however, relationship of rainfall to forest cover is directly related for the Betwa river basin. Above analysis shows that temperature response to vegetation was different for pre-monsoon and post-monsoon seasons.

Regression analysis shows that there was difference in response of climatic factors on forest area and vegetation for the BRB. In pre-monsoon season, there was a significant response between forest cover and temperature, vegetation and temperature; moderate response between vegetation and rainfall; very low response between the forest cover and rainfall. However, post-monsoon season there was a significant response between forest cover and rainfall, vegetation and temperature whereas there was a low response between forest cover and temperature, vegetation and rainfall for the BRB.

\section{Conclusion}

Following conclusions are drawn from the present study:

1. In the pre-monsoon season, the regression analysis of temperature over forest cover and vegetation shows regression coefficient values of 0.6876 and 0.5751 , respectively. However, regression analysis of rainfall over forest cover and vegetation shows regression coefficient value of 0.0875 and 0.3459 , respectively. Forest cover and vegetation were significantly related to temperature only and these two variables were not related to rainfall. Rainfall was not significantly related to forest cover and vegetation by statistical analysis, but graphically it shows that there was small change in positive way.

2. In the post-monsoon season, the regression analysis of temperature over forest cover and vegetation shows regression coefficient value of 0.1206 and 0.6854 , respectively. However, regression analysis of rainfall over forest cover and vegetation shows regression coefficient value of 0.8417 and 0.0027 , respectively in post-monsoon season, rainfall exhibited significant positive response to forest cover and temperature exhibited negative response to vegetation.

3. In BRB, temperature response was different for vegetation in pre-monsoon and post-monsoon season.

4. Study revealed that, the effect of climate is significant on forest cover with temperature (pre-monsoon season) while forest cover with rainfall (post-monsoon season) and vegetation with temperature (pre- monsoon and post-monsoon season), which can be monitored with the help of satellite data.

Acknowledgments Authors are thankful to Indian Institute of Technology Roorkee and Ministry of Water Resources, Government of India, New Delhi for providing financial assistance to carry out this research work. We thankfully acknowledge the facilities and support provided by the Department of Water Resources Development and Management, IIT Roorkee during this study.

Open Access This article is distributed under the terms of the Creative Commons Attribution License which permits any use, distribution, and reproduction in any medium, provided the original author(s) and the source are credited. 


\section{References}

Ahlawat R (2010) Space-time variation in rainfall and runoff: upper Betwa catchment. Int J Environ Earth Sci 1(2):90-96

Chakraborty K (2009) Vegatation change detection in Baeak Basin. Curr Sci 96(9):1236-1242

Chandrabose AS, Viswanath GK, Giridhar MVSS, Sridhar P (2012) Assessment of land use land cover changes in middle Godavari (G-5) sub-basin of river Godavari using RS and GIS. XIX International Conference on Water Resources, pp 17-22

Gopalakrishnan R, Jayaraman M, Bala G, Ravindranath NH (2011) Climate change and Indian forests. Curr Sci 101(3):348-355

Joshi VU, Nagare V (2009) Land use change detection along the Pravara river basin in Maharashtra, using remote sensing and GIS techniques. AGD Landsc Environ 3(2):71-86

Lyon JG, Yuan D, Lunetta RS, Elvidge CD (1998) A change detection experiment using vegetation indices. Photom Eng Remote Sens 64(2):143-150

Pielke RA, Dutta D, Niyogi S, Chase TN, Eastman JL (2003) A new perspective on climate change and variability: A focus on India. Proceedings Indian National Science Academy., vol 69-A, no. 5, pp 585-602

Rajagopalan G, Sukumar R, Ramesh R, Pant RK, Rajagopalan G (1997) Late quaternary vegetational and climatic changes from tropical peats in southern India-an extended record up to 40,000 years BP. Curr Sci 73(1):60-63
Ravindranath NH, Joshi NV, Sukumar R, Saxena A (2006) Impact of climate change on forests in India. Curr Sci 90(3):354-361

Richardson AJ, Everitt JH (1992) Using spectral vegetation indices to estimate rangeland productivity. Geocarto Int 7(1):63-69

Sakthivel R, Manivel M, Jawaharraj N, Pugalanthi V, Ravichandran N, Anand VD (2010) Remote sensing and GIS based forest cover change detection study in Kalrayan hills, Tamilnadu. J Environ Biol 31(5):737-747

Sarkar S, Kafatos M (2004) Interannual variability of vegetation over the Indian sub-continent and its relation to the different meteorological parameters. Remote Sens Environ 90:268-280

Sreenivasulu V, Bhaskar PU (2010) Change detection in landuse and landcover using remote sensing and GIS techniques. Int J Eng Sci Technol 2(12):7758-7762

Tiwari RC (2006) Analytical study of variation of climatic parameters at Aizawl, Mizoram (India). Bull Arunachal For Res 22(1\&2): 33-39

Tsarouchi GT, Buytaert W (2013) Monitoring land use changes in the Upper Ganga Basin, India by using Remote Sensing and GIS techniques on Landsat 5 TM data. Geophys Res Abstr 15:229

Wie PV, Stein M (1977) A landsat digital image rectification system. IEEE Trans Geosci Electron GE-15(3):130-137

Zhang M, Carder K, Muller-Karger FE, Lee Z, Goldgof DB (1999) Noise reduction and atmospheric correction for coastal applications of landsat thematic mapper imagery. Remote Sens Environ 70:167-180 